\title{
A política de treinamento dos servidores técnico- administrativos da Universidade Federal de Viçosa (UFV) na percepção dos treinados e dos dirigentes da instituição*
}

\author{
Elenice Maria de Magalhães** \\ Adriel Rodrigues de Oliveira*** \\ Nina Rosa da Silveira Cunha**** \\ Afonso Augusto Teixeira de Freitas de Carvalho Lima***** \\ Daniela Cristina da Silveira Campos******
}

SumÁrio: 1. Introdução; 2. Recursos humanos no setor público; 3 . Treinamento, desenvolvimento e educação (TD\&E); 4. Legislação federal do servidor público relativa a T\&D; 5. Metodologia; 6. Análise do caso UFV; 7. Análise geral do aperfeiçoamento na UFV; 8. Considerações finais.

Summary: 1. Introduction; 2. Human resources in the public sector; 3 . Training, development and education (TD\&E); 4. Federal legislation on government employee training and development; 5. Methodology; 6 . Analysis of the UFV case; 7. General analysis of the improvement at UFV; 8. Final remarks.

Palavras-chave: políticas de recursos humanos; treinamento e desenvolvimento; organização pública.

\footnotetext{
* Artigo recebido em dez. 2007 e aceito em mar. 2009.

** Mestre e bacharel em administração pela Universidade Federal de Viçosa (UFV). Endereço: Rua General Canabarro, 165, ap. 106 - Maracanã - CEP 20271-202, Rio de Janeiro, RJ, Brasil. E-mail: elemagalhaes@yahoo.com.br.

*** Doutor em administração. Professor associado da UFV. Endereço: Rua Otávio Silva Araújo, 26 - Belvedere - CEP 36570-000, Viçosa, MG, Brasil. E-mail: aroli@ufv.br.

**** Doutora em economia aplicada. Professora associada da UFV. Endereço: Condomínio Acamari, 28 - Acamari - CEP 36570-000, Viçosa, MG, Brasil. E-mail: ninarosa@ufv.br.

***** Doutor em engenharia de produção. Professor adjunto da UFV. Endereço: Departamento de Administração - Av. Peter Henry Rolfs, s/no - Campus Universitário - CEP 36570-000, Viçosa, MG, Brasil. E-mail: afonsoli@ufv.br.

$* * * * * *$ Mestre e bacharel em administração pela UFV. Endereço: Rua Padre Virgulino, 689, ap. 301

— Centro — CEP 39800-025, Teófilo Otoni, MG, Brasil. E-mail: daniadm2000@yahoo.com.br.
} 
KEY WORDs: human resource policies; training and development; public organization.

Desde a década de 1990, o setor público brasileiro tem buscado modificar sua atuação perante a sociedade. Em um contexto de reformas, a área de recursos humanos tornase essencial, pois são as pessoas que colocam em prática tais mudanças. Uma política de recursos humanos imprescindível para o êxito das reformas é o treinamento, que possibilita a capacitação do funcionário para um melhor desempenho na prestação de serviços aos cidadãos. Este artigo identifica o modo como o treinamento dos servidores técnico-administrativos (STAs) influencia a realização das atividades na Universidade Federal de Viçosa (UFV), na percepção dos treinados e dos dirigentes da instituição. As informações foram obtidas por meio de uma revisão da literatura, de visita à diretoria de recursos humanos da UFV, e de entrevistas com alguns treinados e dirigentes da instituição. De acordo com os resultados, existem diversos fatores que interferem positiva e negativamente no processo de treinamento. A falta de uma política de aperfeiçoamento formalizada e a legislação contribuem para essa realidade. Como o processo não é bem estruturado, não existe um planejamento para as atividades de treinamento, nem mesmo uma avaliação do STA que o fez.

Training policy for the technical-administrative staff at the Federal University of Viçosa (UFV) as perceived by trained employees and managers

Since the 1990s the Brazilian public sector has made an effort to improve its performance. In a context of reforms, the human resources area is essential, because it is people who make the change. A human resource policy crucial for the reforms' success refers to training, which gives the employees the skills needed to improve his/hers performance while serving the public. This article identifies the ways in which the training of technical-administrative staff (TAS) influences the activities at the Federal University of Viçosa, UFV (in the state of Minas Gerais, Brazil), according to the trained employees and the management. The information was obtained by reviewing the literature, visiting the human resources department and by interviewing a few employees and managers. The results show that there are two factors interfering in the training process, both positively and negatively. The lack of an official improvement policy and the legislation contribute to that. Since the process is not well structured, there is no planning for the training activities, as well as no evaluation of the TAS that underwent this process.

\section{Introdução}

Nas últimas décadas do século XX, alguns países iniciaram um movimento para discutir o modelo de gestão adotado pelos governos, tendo como propósito mudanças no gerenciamento do setor público, que poderiam tornar as organizações mais ágeis e eficientes, reduzir os custos e melhorar a satisfação 
no atendimento às necessidades da sociedade. No Brasil, as mudanças na forma de atuação do setor público iniciaram-se, a partir da década de 1990, com a criação do Plano Diretor da Reforma do Estado (Marconi, 2005).

As mudanças no setor público brasileiro são mencionadas por Olivier (2001) afirmando que, embora tenham sido iniciadas para maior profissionalização da gestão pública, são ainda pouco significativas, principalmente em relação à área de recursos humanos. Em muitas organizações públicas, observa-se certa dificuldade na adoção de novas técnicas de gestão de recursos humanos $(\mathrm{RH})$, resultando em defasagem em relação à evolução do mercado e às mudanças na gestão de RH. Na concepção de Marconi (2005) há necessidade de desenvolvimento da área de recursos humanos no setor público, de modo a criar condições para solução de alguns problemas ainda presentes, como a desmotivação dos funcionários e a precariedade no atendimento aos cidadãos.

No que se refere às políticas de recursos humanos no setor público, especialmente treinamento, autores como Gaetani (1998), Nunberg (1998) e Pacheco (2002) comentam que, na maioria das instituições públicas, não existem políticas definidas para o desenvolvimento do funcionário pelo treinamento e a progressão na carreira. Além disso, o conhecimento dos servidores públicos, em algumas situações, é limitado, o que se reflete na realização de um trabalho inferior ao exigido, não correspondendo às necessidades atuais dos cidadãos. Essa situação demanda trabalho efetivo de modo a dar atenção especial à capacitação permanente dos servidores, por meio do treinamento.

Nas instituições federais de ensino superior (Ifes), Olivier (2001) afirma que a área de RH encontra-se em situação que impede, muitas vezes, a aplicação dos princípios básicos da gestão de $\mathrm{RH}$, a começar pela indicação de pessoas sem o perfil profissional condizente ao seu efetivo gerenciamento ou mesmo despreparadas. Outro fator restritivo respalda-se na ampla existência de leis e demais instrumentos legais que dificultam a implementação de políticas integradas de recursos humanos. Quanto à política de treinamento, não se encontra impregnada de uma visão mais ampla e sistêmica de forma a se integrar com as demais políticas de $\mathrm{RH}$ e nem tampouco com o seu próprio processamento, faltando integração entre suas fases. Constata-se também que as progressões de carreira dos servidores técnico-administrativos são limitadas, em função da legislação que permite a mudança entre cargos de níveis diferentes, somente por meio de novo concurso público. Esta situação resulta em casos nos quais o funcionário, após realizar um curso superior, tem que continuar ocupando cargos de nível médio, sem que a universidade possa recompensá-lo por seus esforços, contribuindo para que nem sempre utilizem seus novos conhecimentos no cargo que ocupam. 
No caso específico da UFV, o treinamento dos servidores técnico-administrativos é dividido, de acordo com a Resolução no 10/88 do Conselho Universitário (Consu), em aperfeiçoamento e treinamento. O aperfeiçoamento constitui os cursos formais de longa duração, em nível de pós-graduação, nas modalidades de especialização, mestrado, doutorado e pós-doutorado. ${ }^{1} \mathrm{O}$ treinamento abrange os cursos de curta duração, que são as reuniões, congressos e outras atividades de natureza técnico-científico-cultural. Até o momento da realização desta pesquisa, não existia uma política formalmente definida para a área de $\mathrm{RH}$, de acordo com as informações obtidas junto à diretoria de recursos humanos (DRH). Quanto ao treinamento, ao que tudo indica, não há um trabalho voltado para o estudo do seu custo-benefício, pois, quase nunca é realizado de acordo com as necessidades da instituição, mas conforme interesses do funcionário.

Diante do contexto de reformas na gestão pública, que têm como propósito a melhoria na prestação de serviços à sociedade, com o foco na área de $\mathrm{RH}$, especialmente na capacitação, o objetivo do presente trabalho foi identificar o modo como o processo de aperfeiçoamento dos servidores técnico-administrativos influencia a realização das atividades na UFV, na percepção dos treinados e dirigentes da instituição.

\section{Recursos humanos no setor público}

Na concepção de Marconi (2005), a área de recursos humanos em muitas organizações públicas exerce, ainda, papel tradicional no desempenho de funções que se restringem às rotinas de processamento de tarefas administrativas relacionadas ao pagamento, aos benefícios da aposentadoria e afins, proposição de leis, regras e outros regulamentos relativos à área. Comenta que as mudanças na forma de sua atuação estão ocorrendo de forma lenta, gradativa, sendo necessária a implementação de muitas ações para que sejam percebidos resultados efetivos.

As transformações no papel de RH começaram a partir do momento que a administração pública constatou a necessidade de alterar, profundamente, $o$ perfil da força de trabalho, em direção a um quadro mais qualificado de servidores. Significa dizer que a reforma do Estado teve como um de seus propósi-

\footnotetext{
${ }^{1}$ Cabe mencionar que o pós-doutorado não se trata de curso formal, mas, sim, de um programa de trabalho acadêmico de natureza diversa.
} 
tos dar atenção especial à profissionalização de seus recursos humanos. Nessa linha de raciocínio, Gaetani (1998:3) comenta que, até então, a área de RH era uma temática sem espaço nos processos de formulação e implementação de políticas públicas. Ressalta que: "Apenas com as macrotransformações iniciadas nos anos 1980, direcionadas para a reforma do aparato governamental, a problemática de recursos humanos no setor público começou a ser focalizada com atenção especial".

A política de recursos humanos no setor público é discutida por Farias e Gaetani (2002), associando-a à profissionalização da administração pública. Assim, os principais pontos de mudança concentram-se nos seguintes elementos: institucionalização do princípio do mérito nas políticas de recrutamento, seleção e promoção de funcionários; gerenciamento da força de trabalho, bem como de suas necessidades de alocação e dimensionamento; realização de investimentos em recursos humanos pela promoção de programas de capacitação, orientados para dirigentes, quadros de carreira e empregados públicos em geral; gestão integrada dos recursos envolvidos; implementação de políticas de recursos humanos; e adoção de mecanismos de avaliação de desempenho, ligados à remuneração diferenciada para resultados satisfatórios.

Ao referir-se à reforma do Estado, Pacheco (2002) declara que um dos objetivos do Plano Diretor era modernizar a administração burocrática, por meio de uma política de profissionalização do serviço público incluindo política de carreiras, de concursos públicos anuais, de programas de educação continuada, de administração salarial e criação de uma cultura gerencial, baseada na avaliação de desempenho. A implementação dessas ações pode contribuir para a criação de uma política de RH integrada no setor público. Nesse sentido, Farias e Gaetani (2002) afirmam que o grande desafio é formular uma política integrada e abrangente de recursos humanos, de modo a proporcionar maior organização e coesão à gestão pública. Ressaltam a existência de muitos temas que ainda não estão bem organizados na área de $\mathrm{RH}$, como a avaliação de desempenho, a competitividade dos salários, a institucionalização de programas de aperfeiçoamento, progressão nas carreiras e a incorporação da área de $\mathrm{RH}$ nos processos de planejamento das organizações públicas.

Nas instituições federais de ensino superior, Olivier (2001) comenta que a área de recursos humanos, inicialmente denominada como departamento de pessoal, preocupava-se exclusivamente com o cumprimento dos aspectos legais relacionados às pessoas. Posteriormente, as unidades gestoras de pessoas nas Ifes atingiram o nível hierárquico de gerência, às vezes diretoria de recursos humanos, mas, em muitos casos, ainda não possuíam as características necessárias para receberem essa denominação. O discurso dos gestores das 
Ifes e dos responsáveis pelos recursos humanos demonstra a necessidade de inserção da área no nível estratégico de decisões.

Uma característica que deve ser considerada no caso das universidades, é que semelhante às demais organizações do setor público sua estrutura é burocrática, se adequando mais à chamada burocracia profissional. A burocracia profissional vem da denominação dada por Mintzberg (1995) às organizações com base na padronização de habilidades, tendo a ênfase na autoridade de natureza profissional. Trata-se de uma estrutura democrática, pelo menos para os profissionais do núcleo operacional que são os docentes. Esses profissionais não somente controlam seu próprio trabalho, como também buscam o controle coletivo sobre as decisões administrativas que os afetam. Esse controle é feito por indicação dos próprios pares para realizar parte do trabalho administrativo. No caso dos professores, eles participam e presidem colegiados, além de ocuparem cargos de chefia, o que lhes garante algum controle sobre as decisões que influenciam seu trabalho, resultando em algumas situações nas quais não é dada a devida atenção para algumas áreas dessas instituições, como o desenvolvimento de $\mathrm{RH}$.

Marques (2002) comenta que têm ocorrido algumas mudanças para a agilização do fluxo dos processos de trabalho na administração pública. Nesse conjunto está incluída a universidade, o que implica o desenvolvimento de modelos de gestão capazes de criar e manter um clima organizacional, que seja favorável e contribua para os resultados da instituição, por meio da formação de equipes, que possuam características direcionadas para a produtividade e competitividade. Esse contexto demanda necessidade de valorização da área de RH nas Ifes, especialmente no que se refere à qualificação dos servidores. Essa necessidade é ressaltada por Grillo (1990), mencionando expectativa em relação à criação, nas universidades, de um sistema de aperfeiçoamento do pessoal técnico-administrativo, contemplando, inclusive, a criação de um programa com orçamento específico.

As mudanças em relação à área de RH nas organizações públicas, especialmente nas universidades, estão acontecendo, mesmo que em intensidades diferentes. Em algumas universidades federais, como Universidade Federal de Goiás (UFG), Universidade Federal do Paraná (UFPR), Universidade Federal de Santa Catarina (UFSC), Universidade Federal de Minas Gerais (UFMG) e Universidade Federal de Juiz de Fora (UFJF), criaram-se pró-reitorias de recursos humanos, com ações direcionadas para o desenvolvimento de seus servidores. Todavia, na prática, parece existir uma carência de ações integradas em relação aos recursos humanos no setor público. Em muitos casos, ocorrem ações isoladas que, embora tragam mudanças em algumas políticas, 
não abrangem todo o âmbito de recursos humanos, razão pela qual seus resultados nem sempre são visíveis e satisfatórios.

\section{Treinamento, desenvolvimento e educação (TD\&E)}

As mudanças que estão ocorrendo com frequência, diversidade, profundidade e rapidez cada vez maiores têm contribuído para uma preocupação generalizada de diversos setores da sociedade quanto à qualificação pessoal. Impõe-se cada vez mais pensar que a questão da qualificação de pessoas é objeto de interesse de diversos segmentos sociais e não apenas de escolas e empresas. Nesse sentido, pretende-se abordar considerações sobre a importância da qualificação do indivíduo para atender às exigências do mercado, apresentando a definição dos principais termos referentes à qualificação pessoal que são a educação, o treinamento e o desenvolvimento.

A educação em seu sentido amplo é definida, por Chiavenato (1994:415), como "toda influência que o ser humano recebe do ambiente social, durante toda sua existência, no sentido de adaptar-se às normas e valores sociais vigentes e aceitos". Existem vários tipos de educação, entretanto, neste artigo, o interesse está voltado para a educação profissional, que tem como propósito preparar o indivíduo para a vida profissional. Na opinião de Carvalho (1988:4), "a educação envolve todos os aspectos pelos quais a pessoa adquire compreensão do mundo que a cerca, bem como a necessária capacidade para melhor lidar com seus problemas". É um processo em que o ser humano é influenciado, continuamente, pelo meio em que vive. Ressalta a dificuldade de separar o processo de treinamento da educação, uma vez que a atividade de treinamento é uma forma de educação especializada, cujo propósito é preparar a pessoa para o desempenho eficiente de uma determinada tarefa a ela atribuída. Nessa linha de raciocínio, Carvalho (1988:5) sintetiza a relação entre educação e treinamento, afirmando:

A educação denomina-se "instrução" quando o indivíduo recebe formação escolar em seus vários graus de ensino. Mas a instrução continua a ser parte atuante da educação sob perspectiva formal. $\mathrm{E}$ o treinamento, dando continuidade à educação, prepara o empregado para melhor exercer suas funções profissionais.

Para Milioni (2001:10), o treinamento "é a ação sistematizada de educação para a capacitação, o aperfeiçoamento e o desenvolvimento do indivíduo". Entretanto, na concepção de Gil (2001:121), treinamento é "o meio 
para adequar cada pessoa a seu cargo, com vista no alcance dos objetivos da organização". O que se verifica, atualmente, é que o processo de treinamento precisa desenvolver competências nas pessoas, no sentido de tornarem-se mais produtivas e contribuir para a organização. Por essa razão, quando se refere à capacitação de pessoas, a tendência é falar em desenvolvimento de pessoas ou educação no trabalho. Assim, desenvolver pessoas significa: oferece-lhes a formação básica para que transformem antigos hábitos, desenvolvam atitudes e capacitem-se para melhorar seus conhecimentos, buscando tornarem-se melhores na realização do trabalho.

Nesta pesquisa, optou-se por utilizar o conceito de treinamento que sintetiza a ideia de alguns estudiosos do tema (Chiavenato, 1999; Ferreira, 1989; Gil, 2001). Portanto, o treinamento refere-se a qualquer ação sistematizada, que busca oferecer, ao indivíduo, conhecimentos e habilidades para o adequado desempenho de suas tarefas no cargo que ocupa. O conceito de desenvolvimento adotado vai além do treinamento, uma vez que prepara o indivíduo para uma atuação futura, por meio de seu desenvolvimento profissional.

Há que se considerar que com a evolução das teorias administrativas, especialmente a teoria de sistemas, e as mudanças constantes no contexto organizacional, o processo de treinamento passou a ser visualizado com a abordagem sistêmica. Segundo Gil (2001), o treinamento é um sistema que abrange diversos subsistemas compostos pelo diagnóstico, prescrição, execução e avaliação. Ressalta que o enfoque sistêmico possui a vantagem de incorporar várias contribuições científicas ao treinamento. Borges-Andrade (1982), citado por Lacerda e Abbad (2003), também concordam que o treinamento deve ser entendido como um conjunto de atividades interdependentes ou um subsistema, no qual são levantadas as necessidades de treinamento, por meio das quais é elaborado o planejamento, que permitirá uma orientação para a execução e avaliação do treinamento. A avaliação possibilitará um feedback com os ajustes necessários para os outros componentes do sistema.

Ao referir-se ao treinamento, Chiavenato (1999) afirma que deve constituir uma atividade contínua, constante e ininterrupta na organização. Isso significa que, mesmo quando os funcionários demonstrarem um excelente desempenho, ainda há algo a melhorar, no sentido de alcançar um novo patamar de desempenho futuro. Portanto, alguma orientação e melhoria das habilidades sempre deve ser inserida ou incentivada. Nessa mesma perspectiva, Carvalho (1988:120) declara:

Formação profissional é, essencialmente, um processo irreversível de aperfeiçoamento. O treinando necessita, constantemente, adquirir novos conhecimentos, 
habilidades e atitudes. Por essas razões, a continuidade da capacitação deve ser feita conforme a periodicidade exigida pela natureza das tarefas executadas pelo funcionário.

Existe consenso entre alguns estudiosos (Carvalho, 1988; Chiavenato, 1999; Gil, 2001) de que o treinamento constitui um processo composto por quatro etapas interligadas: diagnóstico das necessidades, planejamento ou programação, execução e avaliação. A primeira etapa, diagnóstico das necessidades, envolve a análise no nível da organização, das tarefas e do indivíduo. Para Milioni (2001), essa etapa consiste na busca de informações que levem a uma conclusão sobre o alcance dos objetivos propostos para um acontecimento, que nesse caso é melhorar a atuação do funcionário no cargo por meio do treinamento.

A segunda, planejamento e programação, refere-se à elaboração do programa de treinamento para atender às necessidades levantadas (quem deve ser treinado, como, em que, por quem, onde e quando) com a finalidade de atingir os objetivos do treinamento. Para Harazim (2001), o planejador, ao elaborar o plano, deve ter cuidado com a distinção entre o treinamento de conhecimentos, de habilidades e de comportamentos, uma vez que os conhecimentos se aprendem estudando; as habilidades, por meio de exercício; e os comportamentos, por meio de decisão pessoal e feedback.

A terceira, execução ou implementação, diz respeito à aplicação e condução do programa de treinamento. Por fim, a avaliação, que ao verificar os resultados do treinamento, busca-se identificar se os objetivos do treinamento foram alcançados. Segundo Milioni (2001), os gestores de treinamento e desenvolvimento devem elaborar seus projetos de treinamento, levando em consideração a avaliação de resultados como um processo menor dentro do processo de $T \& D$, que se subdivide em quatro níveis (reação, aprendizagem, mudança de comportamento no cargo e resultados organizacionais). Cada um desses níveis é, igualmente, importante na identificação dos resultados alcançados com o programa de treinamento.

$\mathrm{Na}$ avaliação dos resultados do treinamento, deve-se considerar a importância de algumas variáveis como determinantes, entre elas estão as características individuais dos treinandos, relacionadas à motivação para aprender e para transferir a aprendizagem. "A motivação para treinar ou motivação para aprender pode ser definida como direção, esforço, intensidade e persistência com que os treinandos se engajam nas atividades orientadas para a aprendizagem antes, durante e depois do treinamento" (Lacerda e Abbad, 2003:82). Afirmam que a extensão na qual os indivíduos estão motivados para 
aplicar o conteúdo que aprenderam durante o treinamento constitui outro estado afetivo que deve ser identificado ao final do treinamento, referindo-se à motivação para transferir, ou seja, é a capacidade e disposição do participante de utilizar, no trabalho, o aprendido no treinamento.

Em se tratando de treinamento no setor público, Marconi (2005) ressalta que na maioria das instituições públicas não existem políticas definidas para o desenvolvimento do funcionário pelo treinamento e a progressão na carreira. Essa situação carece de modernização e atualização da força de trabalho, para atender às mudanças constantes nas exigências dos cidadãos. Nunberg (1998) afirma que os processos de ascensão na carreira e programas de treinamento adequados para os servidores públicos são praticamente inexistentes em muitos países, inclusive no Brasil. Ressalta que as iniciativas de treinamento para o desenvolvimento de dirigentes precisam ser aprofundadas na administração pública e, além disso, os mecanismos de avaliação de desempenho precisam ser aprimorados. O desafio é demonstrar como os investimentos em profissionalização melhoram os resultados do serviço público.

As mudanças na área de recursos humanos, com a reforma do Estado, englobam um trabalho efetivo no sentido de dar atenção especial à capacitação permanente dos servidores pelo treinamento. Conforme Pacheco (2002), a partir de 1995 foram intensificados os treinamentos na Escola Nacional de Administração Pública (Enap), na Escola de Administração Fazendária (Esaf), além de outras instituições públicas e privadas contratadas pelos diversos órgãos federais. Comenta que o aumento do número de treinamentos foi, em parte, possibilitado por nova visão sobre o papel da capacitação no setor público, pois, tradicionalmente, a capacitação era vista como um requisito para promoção na carreira.

Ainda no que se refere à capacitação no setor público, Pacheco (2002) afirma que a maior efetividade no uso de recursos destinados à capacitação depende, também, de um realinhamento estratégico das áreas de recursos humanos nas organizações públicas. No que se refere aos investimentos em treinamento, existe a hipótese de que se gasta muito com capacitação e não se sabe como esses recursos são gastos, pois, os resultados não são mensurados. Marques (2002), também, comenta que o volume de gastos com a capacitação no âmbito do governo federal é uma indagação, cuja resposta é difícil de ser obtida, uma vez que trata-se de um dado bastante disperso.

Em se tratando do treinamento em Ifes, Grillo (1990) declara que as universidades constituem ambiente propício para o desenvolvimento de programas de aperfeiçoamento e atualização, visto que o quadro de pessoal é composto por grande diversidade de especialistas, tanto no corpo docente 
quanto no de servidores técnico-administrativos. No entanto, declara que mesmo possuindo condições favoráveis, nem sempre a universidade consegue estimular seus servidores no sentido do aperfeiçoamento. Isso porque esse estímulo, em muitos casos, diz respeito à vinculação que o aperfeiçoamento deve ter com a carreira e, no caso das universidades, principalmente para técnico-administrativos, a carreira é pouco motivadora devido a problemas, como política salarial defasada, indefinição de atribuições dos cargos, falta de incentivos e ausência de relação entre treinamento e carreira.

Todavia, na percepção de Marques (2002), as novas exigências advindas de mudanças na gestão pública tendem a demandar das universidades a criação de mecanismos para o incentivo e a valorização dos seus recursos humanos, por meio do desenvolvimento de ações de capacitação, direcionadas para a democratização do saber no âmbito institucional. O desenvolvimento de recursos humanos nas universidades deve estar voltado para a promoção da satisfação dos servidores, que se inserem na esfera das instâncias técnicas e administrativas, visto que o bem-estar e a melhoria da qualidade de vida desses servidores são aspectos diretamente inter-relacionados. Tais propósitos de treinamento e desenvolvimento nas universidades podem ser considerados um avanço, no sentido de tentar melhorar a profissionalização da gestão de $\mathrm{RH}$, o que é coerente com as exigências impostas pelo contexto de modernização do setor público.

\section{Legislação federal do servidor público relativa a T\&D}

Associada às mudanças de percepções sobre a necessidade de treinamento, foi instituída a Política Nacional de Capacitação por meio do Decreto no 2.794 , de $1^{\circ}$ de outubro de 1998. Conforme Pacheco (2002), a política introduziu a noção de público alvo e temas prioritários a serem treinados, bem como uma visão gerencial da capacitação. A proposta era tornar públicos os dados comparativos entre as diversas instituições federais, sobre o gasto com capacitação e o atendimento do público alvo prioritário. No entanto, a sua implementação foi burocratizada, sendo que até 2002 não havia alcançado os resultados previstos, não existindo, portanto, informações gerenciais sobre a capacitação de servidores públicos federais.

Em 23 de fevereiro de 2006, foi instituído o Decreto no 5.707 (Brasil, 2006), que substituiu o Decreto ํㅡ 2.794/98. A nova Política Nacional de Desenvolvimento de Pessoal trouxe algumas poucas inovações para a capacitação dos servidores federais em razão da semelhança à política anterior. Entre 
elas a que diz respeito à possibilidade de acesso aos valores fixados por instituições especializadas em ações de desenvolvimento de recursos humanos. Essa diretriz permite obter parâmetros relacionados aos custos das ações de capacitação, contribuindo para a realização do planejamento orçamentário da organização. Além disso, uma maior publicidade em todo o processo de capacitação pode facilitar a aprovação dos planos nos mais diversos órgãos sem a ocorrência de distorções na aplicação dos recursos financeiros.

As principais inovações do Decreto $n^{\circ} 5.707$ (Brasil, 2006) referem-se à consideração da capacitação de pessoal como um processo contínuo que busca o desenvolvimento de competências organizacionais individuais, preparando, inclusive, as pessoas para assumir cargos futuros. Trabalha também com o conceito de gestão por competências, que se refere a uma abordagem moderna do treinamento.

Em se tratando da legislação que regulamenta o plano de carreira dos servidores técnico-administrativos das Ifes, verifica-se que algumas leis e decretos foram criados ao longo dos anos. Atualmente, a Lei no 11.091, de 12 de janeiro de 2005, dispõe sobre a estruturação do plano de carreira dos cargos técnico-administrativos em educação, o que representou preocupação maior com o assunto. Nos dispositivos dessa lei, podem ser verificados alguns itens que contemplam a valorização do desenvolvimento profissional do servidor no que diz respeito à capacitação com percentuais de incentivos financeiros após a qualificação.

É interessante observar que, embora existam cinco níveis de classificação (A, B, C, D e E), o servidor ao adquirir uma formação superior, além da que lhe é exigida pelo seu cargo, não poderá mudar para o cargo de outro de nível de classificação. A mudança de nível de capacitação e de padrão de vencimento não resultará em mudança de nível de classificação, mas somente no nível de capacitação. Assim, os incentivos à capacitação, proporcionados pela Lei no 11.091 (Brasil, 2005), são importantes, pois podem motivar o servidor no sentido de seu desenvolvimento profissional. Entretanto, são pouco significativos no que diz respeito à possibilidade de crescimento na carreira dos servidores técnico-administrativos, uma vez que ainda não existem meios para o crescimento, através da ocupação de sucessivos cargos na organização pública.

O desenvolvimento desta pesquisa foi baseado na Resolução $n^{\circ}$ 10/88 do Consu, que trata do Regulamento de Aperfeiçoamento e Treinamento do Pessoal Técnico-Administrativo da UFV. De acordo com essa resolução, a UFV, dentro de sua programação, concede autorização ao seu pessoal técnico-administrativo para a realização de atividades de aperfeiçoamento e treinamento. 
Estabelece, ainda, que aos técnicos de nível superior, que se dedicam a atividades acadêmicas (pesquisa e extensão), aplicam-se as mesmas regras de aperfeiçoamento e treinamento dos docentes. Entretanto, quando este artigo se encontrava em fase final de elaboração, o Consu instituiu a Resolução no 11/2006 que trata da Política de Desenvolvimento dos Servidores Técnico-Administrativos da UFV. Ela foi criada, considerando o disposto na Lei ㄲo 11.091/2005 (Brasil, 2005), buscando estabelecer suas finalidades e regimentar as normas para o seu funcionamento, considerando a realidade específica da UFV.

\section{Metodologia}

A pesquisa desenvolvida possui natureza exploratória e descritiva de acordo com Vergara (2005). A pesquisa exploratória é aquela realizada em uma área, em que existe pouco conhecimento acumulado, ou seja, poucos estudos científicos, enquanto a pesquisa descritiva expõe características de determinada população ou de determinado fenômeno, podendo estabelecer associações entre variáveis. Trata-se de um estudo de caso que, de acordo com Yin (2001), possibilita investigar o fenômeno com maior profundidade, dentro de seu contexto, não interferindo em suas características significativas. A opção pela utilização do estudo de caso deve-se ao fato de haver poucos estudos na área de treinamento em Ifes. Assim, optou-se por estudar de forma mais intensa uma realidade específica, que é a da UFV.

Este artigo foi realizado em 2006. A população alvo da pesquisa foi constituída por todos os servidores técnico-administrativos que fizeram aperfeiçoamento, quando já eram funcionários da UFV, constituindo-se de 61 pessoas. Dessa população, identificaram-se aqueles servidores que teriam interesse em participar da entrevista, perfazendo um total de 15 pessoas. Além disso, foram realizadas entrevistas com os seguintes dirigentes da instituição: reitor, vice-reitor, pró-reitor de administração e a diretora de recursos humanos. Para escolha dos dirigentes, identificaram-se aqueles que trabalhavam diretamente na linha de recursos humanos, ou participavam ativamente das decisões referentes ao processo de aperfeiçoamento.

Para coleta e análise de dados, utilizou-se a abordagem qualitativa que, segundo Godoy (1995), não procura enumerar e/ou medir os fatos estudados, mas explorar e revelar fenômenos sobre pessoas, lugares e processos interativos. O estudo de caso se baseou em Yin (2001), que considera, para validade e confiabilidade do estudo, a utilização de várias fontes de evidências, denominada triangulação. Nesta pesquisa, para obter dados de diferentes fontes, 
foram utilizadas análise documental e entrevistas com sujeitos sociais diferentes, ou seja, treinados e dirigentes da instituição.

Inicialmente foi realizada a análise nos documentos referentes aos procedimentos formais para realização do aperfeiçoamento. Na segunda etapa, um roteiro de entrevista semiestruturado foi elaborado e aplicado aos treinados e dirigentes da UFV. O roteiro contemplou questões referentes a: apoio da instituição à realização do aperfeiçoamento; aplicação dos conhecimentos após o retorno às atividades na UFV; influência da legislação que regulamenta a vida profissional do servidor público; resultados do aperfeiçoamento para a instituição e para o técnico; e avaliação do processo de aperfeiçoamento. As entrevistas tiveram duração média de 40 minutos e foram gravadas e transcritas pelo próprio pesquisador. Na transcrição, cada entrevista foi codificada e os entrevistados passaram a ser identificados por meio de código, sendo que os STA treinados receberam códigos do tipo T1, T2, T3... T15, enquanto os dirigentes receberam os códigos D1, D2, D3 e D4.

Para análise das entrevistas, foi utilizada análise de conteúdo por categorização (Bardin, 1977). A definição de categorias ou temas consiste na identificação e agrupamento de elementos sob um título genérico, considerando caracteres comuns desses elementos. A análise de conteúdo possibilitou a identificação das seguintes categorias: tratamento do aperfeiçoamento pela UFV; apoio ao aperfeiçoamento; resultados do aperfeiçoamento; mudanças percebidas com o aperfeiçoamento; influência da legislação no aperfeiçoamento; e avaliação do processo de aperfeiçoamento.

\section{Análise do caso UFV}

A seguir serão apresentadas e discutidas as percepções dos STA e dos dirigentes da UFV a respeito do processo de aperfeiçoamento na instituição, de acordo com as categorias estabelecidas. Cabe lembrar que, durante as análises dos dados, quando os entrevistados fizeram referência ao aperfeiçoamento, utilizaram também os termos treinamento, desenvolvimento e capacitação. Entretanto, quando esses termos forem mencionados, serão limitados ao conceito de aperfeiçoamento adotado na pesquisa (Resolução no 10/88, Consu).

\section{Tratamento do aperfeiçoamento pela UFV}

No que se refere ao modo como o aperfeiçoamento vem sendo tratado pela instituição foram percebidas algumas deficiências. Um aspecto muito citado 
pelos entrevistados refere-se à inexistência de uma política institucionalizada de aperfeiçoamento, que estabeleça normas e diretrizes para a estruturação desse processo, conforme declararam um treinado e um dirigente, respectivamente: "Esse processo na UFV é totalmente desestruturado, falta uma lei ou alguma norma que permita ao técnico fazer o treinamento"; "Na realidade, é no serviço público federal, em todas as Ifes não têm uma política de capacitação e a UFV também não". Apesar da falta de uma política, ficou evidente que a UFV, em geral, permite que seus STA façam o aperfeiçoamento, desde que eles se adaptem às possibilidades oferecidas pela instituição.

Alguns entrevistados demonstraram maior pessimismo em relação às possibilidades para realização do aperfeiçoamento, destacando as diferenças entre as oportunidades dadas aos técnicos dos níveis de apoio, médio e superior, conforme declarou um treinado:

O pessoal que é técnico de nível superior seguia a mesma resolução dos docentes; estes têm aperfeiçoamento, que é educação formal, os outros não. Para os níveis de apoio e médio não existia, algum ou outro servidor, de acordo com a influência que tinha na administração, ele conseguia. Isso acontecia em situações esporádicas e específicas (T14).

Como não existe uma política de aperfeiçoamento com regras bem definidas para o STA, considerando-se as necessidades da instituição e dos diferentes níveis da carreira técnico-administrativa, percebe-se que a realização do aperfeiçoamento ocorre em situações particulares, principalmente para os técnicos dos níveis de apoio e médio. Verifica-se claramente a ausência de formalização do diagnóstico de necessidades, principalmente no âmbito institucional, conciliando de forma coesa e integrativa as necessidades dos servidores. Outra consequência da falta de política é a inexistência de um planejamento para o aperfeiçoamento. Segundo os entrevistados, a instituição precisa planejar o que se espera do STA, estabelecendo um direcionamento para o tipo de atividade que precisa ser feito pelo técnico e, a partir daí, permitir a realização do aperfeiçoamento. A falta de planejamento consistente faz com que o STA realize o aperfeiçoamento mais por interesse próprio e nem sempre de acordo com as necessidades da UFV e, ao retornar do aperfeiçoamento, o técnico tem que buscar meios para tentar aplicar os conhecimentos adquiridos, mas nem sempre consegue.

A questão do aperfeiçoamento na UFV é muito pessoal, não é que a universidade chega perto de você e tem, no planejamento estratégico dela, treinar os 
STA para exercer as funções, que eles desenvolvem dentro da instituição, isto não existe. O que existe é o interesse pessoal do STA e cada pessoa observa isto e busca realizar. A UFV não tem interesse, falta um planejamento. Após se qualificar, a gente tem que criar o ambiente de trabalho, para aplicar os conhecimentos (T11).

Segundo os entrevistados, outra dificuldade é a conciliação do aperfeiçoamento com o trabalho na UFV. Isso se deve ao fato que, em muitos casos, o STA não consegue liberação de suas atividades, para dedicar-se exclusivamente ao aperfeiçoamento. Outro fator dificultador reside na falta do apoio financeiro. Como não existe a definição de um programa bem estruturado que indique o procedimento formal a ser seguido pelo técnico, associado à legislação federal, que não proporciona incentivos financeiros, isso faz com que o técnico não tenha estímulos e incentivos para realizar o aperfeiçoamento.

\section{Apoio para fazer o aperfeiçoamento}

Quanto ao apoio da UFV para o técnico fazer o aperfeiçoamento, foram apontados diversos elementos, que poderiam dificultar este apoio, entre os quais a inexistência de uma política de aperfeiçoamento e de planejamento adequado, que já foram apontados pelos entrevistados. Segundo um dos dirigentes (D3) este apoio nem sempre acontece "porque não existia uma política de capacitação, uma política de desenvolvimento do servidor na carreira".

A legislação também é outro elemento que interfere no apoio da instituição para o técnico se aperfeiçoar. As leis que regem o serviço público estabelecem normas, a exemplo da legislação que não permite a mudança de cargo após o treinamento, a não ser por meio de outro concurso público. Conforme alguns entrevistados, provavelmente, essa é uma das causas que contribui para a UFV não apoiar as iniciativas de aperfeiçoamento, uma vez que ao se aperfeiçoarem, alguns funcionários querem mudar de cargo, gerando problemas para a instituição, já que a lei não permite. "A instituição não tem compromisso de mudar, porque ele (STA) se aperfeiçoou. Agora, para ele mudar para outra posição, tem que fazer outro concurso, pois, a instituição não pode promovê-lo. A lei não permite", colocou um dirigente da UFV. Para determinados entrevistados, é importante que o STA reconheça que a UFV dá apoio, mas dentro dos limites permitidos pela lei.

O apoio ao aperfeiçoamento também está relacionado ao retorno do técnico a seu setor de trabalho, após qualificar-se. Segundo os entrevistados, 
o chefe do STA exerce papel fundamental nesse apoio, pois, pode entender que o aperfeiçoamento será ou não importante para o técnico ou, até mesmo, supor que o treinamento pode constituir ameaça à permanência do técnico no setor, pelo qual esse chefe é responsável. "Estavam (os STA) em posições que o chefe não via necessidade. Infelizmente, tinha muito dos chefes falarem, se ele aperfeiçoar eu vou perder o funcionário" (D1). Tem-se, ainda, o fato do aperfeiçoamento ser em área que não vai contribuir diretamente para as atividades que o técnico executa. Além disso, as qualificações que o cargo exige já foram determinadas no concurso, assim, um aperfeiçoamento poderá não acrescentar muito à rotina de trabalho do técnico, que já tem suas atribuições preestabelecidas. Tais discussões são comprovadas por T7.

Ela (UFV) não apoia porque, no nosso caso, a gente faz concurso para um cargo, então, desenvolve as atividades inerentes àquele cargo. Se você fizer mestrado ou doutorado, muito provavelmente aquilo não vai alterar para a instituição. Então, como na maioria das vezes, isto não vai mudar a rotina de trabalho do STA e não vai acrescentar para a UFV como mão de obra, eu acho que isso cria essa situação.

A descontinuidade administrativa é outro fator que pode influenciar no apoio dado pela instituição à realização do aperfeiçoamento, uma vez que os dirigentes são escolhidos para uma gestão de quatro anos, não existindo, portanto, uma política de longo prazo, no sentido de perceber a contribuição futura do treinado para a UFV. Também, foi mencionada a relação entre STA e docente no que se refere ao receio, por parte dos docentes, de que o técnico ao se qualificar possa tornar-se um concorrente. Então, nos casos em que o professor tem certa influência, pode dificultar o aperfeiçoamento do técnico. Além disso, o trabalho do técnico não é reconhecido como um somatório do trabalho do docente, como importante fator que pode gerar forte contribuição para os propósitos da UFV. Conforme T9 "acho que, em parte, é devido ao medo de concorrência, eles não conseguem observar o trabalho do técnico como um somatório de resultados positivos e, no final, um ganho para a universidade como um todo".

\section{Resultados do aperfeiçoamento}

Em se tratando do atendimento das expectativas com a realização do aperfeiçoamento, todos os STA declararam que, em termos de ganhos pessoais, no que 
se refere à aquisição de conhecimentos e crescimento pessoal, em geral, os resultados foram alcançados. Para determinados STA os resultados foram alcançados tanto em termos pessoais quanto profissionais, no que se refere à utilização dos conhecimentos no trabalho. "Os resultados foram muito positivos tanto para mim como para a UFV, inclusive hoje dentro da minha atividade de técnico, aquilo que eu fiz lá foi extremamente útil" (T12). Para treinados como T3, as expectativas foram até superadas, "Eu alcancei até mais do que eu esperava, abriram alguns campos de trabalho para mim e oportunidades que eu não esperava, inclusive dentro da UFV, portanto, o aperfeiçoamento atendeu às minhas expectativas e foi até além".

Todavia, alguns elementos do processo do aperfeiçoamento que foram apontados, corroboram para que os resultados nem sempre sejam os melhores. Em termos do treinado, o ponto negativo seria a falta de reconhecimento pleno pelo aperfeiçoamento realizado, tanto no sentido financeiro, por meio de aumento salarial compatível com o aperfeiçoamento, quanto no sentido profissional, pois, o técnico especializado nem sempre é bem aproveitado profissionalmente. Nesse sentido, T9 afirma que "o ponto negativo é em termos de salário (...). O pessoal que trabalha nos departamentos está preparado, mas não recebe estímulo. Falta estímulo tanto financeiro quanto moral". Outra questão diz respeito ao treinado não saber o que vai fazer quando volta, pois, como não existe um direcionamento da UFV nesse sentido, o funcionário tem que buscar meios para criar seu espaço de atuação, ou seja, não consegue aplicar os conhecimentos adquiridos como gostaria. Conforme exposto por T3, "ainda não alcancei todos os resultados que esperava. Espero ter mais oportunidades na universidade, para desenvolver mais no que me especializei".

Releva destacar algumas situações e fatores que interferem de forma a prejudicar os resultados. Assim, em algumas situações, os resultados foram muito satisfatórios para o técnico, em termos pessoais, mas nem tanto para a UFV devido à falta de planejamento do que se espera do técnico para, então, direcioná-lo à função que proporcione melhores resultados para a instituição. Essa situação é reflexo da falta de política na instituição e a necessidade de regras e diretrizes bem definidas para o processo de aperfeiçoamento, inclusive no que se refere à função do técnico na UFV e ao modo como o aperfeiçoamento pode contribuir, diretamente, para seu trabalho. É necessário coerência entre o aperfeiçoamento e as atividades executadas pelo técnico, o que nem sempre acontece na instituição.

Eu entendo que um processo de aperfeiçoamento ideal deveria tomar como base, primeiro, qual é a função do servidor e como ele vai desempenhar melhor 
essa função, uma vez que não é nosso papel ter um servidor que atua numa área e quer se aperfeiçoar numa outra, totalmente, diferente. Isto está frequentemente ocorrendo. Tem que haver uma coerência entre a função que o servidor exerce e o aperfeiçoamento realizado, este tem que contribuir para a função que o técnico executa. Então isto não sendo bem estudado como não tem sido na instituição (D2).

Ainda nesse sentido, em se tratando dos resultados do aperfeiçoamento, observa-se que metade dos entrevistados, somente em algumas situações, consegue aplicar os novos conhecimentos no trabalho. Em certas situações, o fato de os conhecimentos não serem utilizados é devido à própria limitação das atividades que o técnico deve desempenhar em seu cargo. Cabe destacar que, se o funcionário fez concurso para determinado cargo, ele só pode mudar para outro cargo por meio de novo concurso. Assim, a instituição não pode permitir que o técnico, que se aperfeiçoou, mude para outro cargo que seja coerente com seu aperfeiçoamento.

Uma parte sim, outra não porque no meu serviço nem sempre tem este espaço. Eu sei que a universidade não tem tanta culpa porque, se eu me concursei para um cargo, não posso almejar um cargo superior, sendo que não sou concursado para aquele cargo (T3).

Outro fator que impede a aplicação de tais conhecimentos é a incoerência entre o aperfeiçoamento e as atividades, que o técnico realiza na UFV. Nesse caso, a instituição não tem nenhum retorno do investimento feito no aperfeiçoamento do STA e este pode ficar insatisfeito por não conseguir aplicar seus conhecimentos em seu ambiente de trabalho. Conforme T14 "como não existia um planejamento institucional para o aperfeiçoamento, ele tornouse um aperfeiçoamento que beneficiou a mim pessoalmente. Não apliquei por que fiz o aperfeiçoamento em administração rural e trabalho em uma próreitoria". Por outro lado, alguns STA declararam ter conseguido aplicar seus conhecimentos nas atividades que executam na UFV. Esses técnicos fizeram o aperfeiçoamento em uma área coerente com as atividades que realizam, o que facilitou a utilização do aprendido. "Sem dúvida apliquei, acho que mesmo eu estando fora agora da área acadêmica, consegui aplicar meus conhecimentos plenamente, pois, hoje trabalho exatamente na área em que me aperfeiçoei", segundo T12.

No que se refere à aplicação dos novos conhecimentos no trabalho, os fatores que mais interferem nessa aplicação foram aqueles já citados, como a 
falta de uma política com planejamento estabelecendo o que a UFV espera do seu STA, a legislação que não permite a mudança de cargo e a incoerência entre a área de atuação e o aperfeiçoamento realizado. Além disso, outros elementos podem dificultar a aplicação dos conhecimentos, como o fato de o técnico, ao fazer o aperfeiçoamento, adquirir uma qualificação que está acima das atividades inerentes ao seu cargo. Além disso, o STA pode ter uma expectativa equivocada de como seu aperfeiçoamento poderá contribuir para a realização de suas atividades. Então, quando o STA retorna à UFV, percebe que nem sempre seus conhecimentos podem ser utilizados de acordo com sua expectativa.

\section{Mudanças percebidas com o aperfeiçoamento}

A realização de qualquer tipo de treinamento envolve mudanças no treinado, referentes a comportamento, desempenho e até mesmo na satisfação do indivíduo, uma vez que ele adquire novos conhecimentos e diferentes formas de pensamento. No caso em estudo, constatou-se que todos os dirigentes já tiveram STA, que realizaram aperfeiçoamento, como subordinados.

As mudanças foram percebidas pelos dirigentes em todos os casos. No entanto, em algumas situações, tais mudanças, embora positivas, não trouxeram os melhores resultados para a instituição, devido a questões mal resolvidas nesse processo, como a falta de uma política que contemple o planejamento para o aperfeiçoamento. Tal situação contribui para que a UFV não tenha um quadro de STA tão especializado como poderia. Além disso, os técnicos que fizeram aperfeiçoamento, às vezes, acabam ficando insatisfeitos no cargo pelo fato de a instituição não ter definido o que se espera deles e qual é seu papel, principalmente o de nível superior. Então, os treinados, nem sempre, aplicam seus conhecimentos como deveriam.

As mudanças com o aperfeiçoamento foram positivas, porque a pessoa consegue sair desse dia a dia maçante e ter a capacidade de criar e abstrair em relação aos próprios conceitos e técnicas de inovar (...). Percebi mudança de desempenho, mas a satisfação no cargo, às vezes, não é muito estimulante, pois, o que a gente vê é que as universidades não encontraram ainda um caminho, no que se refere ao objetivo do técnico administrativo, principalmente o técnico de nível superior (TNS) na instituição. Portanto, essa insatisfação em relação ao cargo tem a ver com isso (D3).

Por outro lado, existem casos em que as mudanças são percebidas, mas o técnico não tem nenhum interesse em aplicá-las, talvez pela incoerência en- 
tre os conhecimentos adquiridos e as atividades que realiza no cargo ocupado. Então, assim que tem uma oportunidade, pede demissão. Essa situação resulta em perdas para a instituição, que investiu no técnico e não terá retorno. Entre as causas que podem contribuir para essas circunstâncias está a falta de um gerenciamento, envolvendo uma política institucionalizada para esse processo que, associado aos interesses particulares dos técnicos, contribui para que o aperfeiçoamento não atenda aos interesses da instituição e dos treinados.

Recentemente, recebi um (técnico) que trabalhava (...). Ele me disse que não pretendia ficar aqui, queria fazer concurso e ir embora. Em geral, as mudanças são mais ou menos complicadas por causa de não ter, do outro lado, essa capacidade de gerenciamento conjunto, porque já tem um sistema frágil que não tem dono. Junta-se aí com a busca particular das pessoas, cada um tem um sonho que não é errado e não pode ser tirado das pessoas. De modo geral, o aperfeiçoamento não está atendendo nem ao servidor nem à instituição. Precisa ser melhorado (D2).

Portanto, percebe-se que o aperfeiçoamento proporcionou mudanças no comportamento dos treinados, o que é coerente com os propósitos do treinamento. Todavia, nem sempre tais mudanças se revertem em prol da UFV, como seria esperado.

\section{Influência da legislação no aperfeiçoamento}

No setor público, todas as ações são respaldadas nas leis, que regulamentam o que pode ou não ser feito. Assim, como tudo que faz parte das organizações públicas é regido pelas leis, na vida profissional, o servidor público só pode fazer o que não é vetado pela legislação. No caso do aperfeiçoamento da UFV, certos entrevistados declararam que as leis influenciam e, embora possam engessar e inibir as ações na organização pública, estas são necessárias ao processo, visto que possibilitam maior controle. Para D2 as leis, "normalmente, influenciam o processo porque, na realidade, o processo público é um processo que não tem muito controle sobre a situação e por não ter controle, ninguém, basicamente, se reporta a ninguém".

Durante as entrevistas, abordou-se também a necessidade de mudança das leis no serviço público pelo fato de a legislação, atualmente, não permitir que o funcionário mude de cargo, a não ser por meio de outro concurso público. O servidor que foi contratado para determinado cargo possui os requisitos 
para realizar as atribuições daquele cargo; assim, ao realizar um aperfeiçoamento, muitas vezes, ele adquire uma qualificação maior do que aquela exigida para seu cargo. Nessa situação, o STA não pode mudar para um cargo que seja mais coerente com seu nível de qualificação. Por isso, segundo os entrevistados, a lei tem que ser revista de modo que permita a mudança de cargo dentro da instituição.

O técnico faz concurso para um cargo com determinadas atribuições, então, qual a vantagem de se capacitar? A vantagem é institucional e para o servidor sempre é vantajoso. Se o servidor tivesse uma possibilidade de ascensão na carreira que não fosse através de novo concurso público, talvez fosse mais interessante. Nesse ponto, ela (a lei) amarra e dificulta, pois, não pode mudar de cargo porque fez o aperfeiçoamento (T7).

No momento em que esta pesquisa se encontrava na etapa de coleta de dados, estava em fase de aplicação inicial a Lei no 11.091/2005, que trata do plano de carreira dos servidores técnico-administrativos. Quanto à influência dessa lei no processo de aperfeiçoamento na UFV, constatou-se que existem opiniões bastante divergentes. Para um grupo de entrevistados, a nova lei vai contribuir, positivamente, no aperfeiçoamento, visto que, até então, não existia uma legislação que contemplasse, detalhadamente, o treinamento dos STA, incluindo os cursos de aperfeiçoamento. A Lei no 11.091 estabelece que as instituições devem ter um programa anual de treinamento, incluindo cursos de curta e longa duração, como é o caso do aperfeiçoamento. Por isso, ela é considerada um avanço na questão do treinamento dos servidores técnico-administrativos das Ifes.

Pode, eu acho que vai influenciar muito. Tudo numa organização pública é muito em torno do que está escrito na lei. Então, agora a gente tem um plano que prevê incentivo à qualificação, que todas as Ifes têm que ter um programa anual de capacitação (...). Antes a lei desestimulava porque não dava incentivo financeiro, agora acho que essa situação vai mudar um pouco por causa do estímulo que vai ter (D3).

Um aspecto positivo da Lei no 11.091 , ressaltado pelos entrevistados, é que ela prevê incentivos financeiros para o aperfeiçoamento que, até então, praticamente não eram contemplados na legislação. De acordo com T11 "ela (Lei no 11.091) pode influenciar, positivamente, porque dá o direito de fazer o aperfeiçoamento e dá vantagens financeiras pelo aperfeiçoamento". Os en- 
trevistados afirmaram que esses incentivos são importantes, mas que ainda podem ser melhorados, dado o esforço que o técnico realiza para fazer o aperfeiçoamento. Foram identificadas percepções de que a Lei no 11.091 , se por um lado deixa explícito que o técnico pode fazer o aperfeiçoamento, por outro não avançou muito no plano de carreira dos STA. "Ela (Lei no 11.091) melhorou um pouco porque reconhece nosso direito de fazer mestrado e doutorado, mas continuamos sem plano de carreira", declarou T9.

Por outro lado, foram obtidas opiniões, segundo as quais a Lei no 11.091 influenciou negativamente o aperfeiçoamento, considerando-se os níveis de apoio, médio e superior da carreira técnico-administrativa. A maioria dos entrevistados, que eram TNS, declarou que ela foi extremamente prejudicial para o nível superior, pois não representou aumento salarial para esse nível, ao contrário de algumas classes dos outros níveis que tiveram aumentos significativos. Os TNS mencionaram, ainda, que não foram reconhecidos pela qualificação que possuem, o que representa uma grande falta de incentivos para a carreira de nível superior na instituição.

A Lei no 11.091 é problemática no sentido de que não considerou os servidores mais qualificados, os técnicos de nível superior, mesmo os técnicos de nível médio foram altamente prejudicados. Nesse sentido, a lei influenciou de forma negativa. É difícil ter uma satisfação maior dos TNS na UFV, pois, foram prejudicados diretamente no salário, houve um achatamento da carreira, foi muito ruim (D4).

Outro problema relativo à Lei no 11.091 é que ela não valorizou alguns cursos de aperfeiçoamento, que o STA já possuía. Assim, se o técnico tem uma especialização e faz um mestrado, a especialização não é mais válida para efeito de incentivos. Além disso, essa lei pode levar a um resultado negativo, no longo prazo, em termos de qualificação. Isso pelo fato de que, em alguns casos, os técnicos acreditarem que precisam se capacitar para subir de nível e melhorar seu salário, e não se preocuparem em como essa qualificação pode contribuir com a instituição. Então, podem acabar fazendo cursos que não vão lhe proporcionar crescimento pessoal e profissional.

\section{Avaliação do processo de aperfeiçoamento}

Os entrevistados fizeram uma avaliação do processo de aperfeiçoamento como um todo, apontando críticas, pontos positivos e sugestões para melhorá-lo. 
Conforme evidenciado, na UFV, esse processo apresenta algumas deficiências que precisam ser trabalhadas. Para certos entrevistados, não é possível avaliar o processo de aperfeiçoamento, uma vez que ele não existia até então. Com a aplicação da Lei no 11.091, somente daqui a algum tempo será possível fazer uma avaliação de como se encontra a questão do aperfeiçoamento.

Na verdade, até então não havia uma política. Agora é aguardar, para ver o que vai acontecer com essa nova legislação (Lei no 11.091 ). Você não pode melhorar o que não existia, a gente vai poder falar disso daqui a um ou dois anos, agora está instituído. Para mim, não existia porque não era uma lei para todos. Eu só consigo admitir que possa ser avaliada uma coisa que é para todos. Então, em termos de programa de aperfeiçoamento e de capacitação, a gente só poderá fazer comentário daqui a algum tempo, quando esse processo estiver consolidado (T14).

Outros entrevistados admitiram que o processo existe, mas é totalmente desestruturado como resultado da falta de um planejamento em que conste a definição do papel do técnico na instituição, o que já foi apresentado como um problema nesse processo. Além disso, a vontade política foi apontada como uma questão que interfere na liberação do técnico para fazer o aperfeiçoamento, sendo que esta, em certos casos, sobrepõe-se à legislação quando o STA demonstra interesse para realizar o aperfeiçoamento, ou seja, é dependente da influência do funcionário. Portanto, são necessárias regras bem definidas para que todos tenham direitos iguais. Nesse sentido, há esperança de que a Lei no 11.091 possibilitará a definição de regras e uma melhor estruturação desse processo. Ainda na avaliação do processo, uma dificuldade, mais uma vez ressaltada, é a oportunidade para aplicação dos conhecimentos adquiridos, o que poderia ser facilitado se o funcionário pudesse mudar de cargo dentro da instituição.

Diante do contexto do aperfeiçoamento foram apresentadas algumas sugestões para seu aprimoramento. Há necessidade da criação de uma política de aperfeiçoamento que seja institucionalizada, envolvendo a conscientização das pessoas sobre a importância do treinamento. Afirmaram, ainda, que é preciso criar uma cultura de reconhecimento do treinado, que refletirá na motivação e qualidade do trabalho do STA, contribuindo para os resultados da UFV.

Acho que falta uma política. Para a área dos STA precisa virar uma política, mas isso depende de todos e não só da instituição, todo mundo tem que se conscientizar da importância do treinamento, o que já está acontecendo. Tem que primeiro 
capacitar as chefias para motivar os subordinados e mostrar a importância do treinamento e, além disso, reconhecer o conhecimento do subordinado. O reconhecimento sensibiliza muito mais do que o financeiro. Temos que trabalhar mais o reconhecimento, se você tem reconhecimento, fica motivado (D1).

A criação de uma política de aperfeiçoamento foi colocada, destacandose a necessidade de contemplar um diagnóstico do modo como o funcionário atua no ambiente de trabalho, antes e após o aperfeiçoamento. Isso diz respeito a um levantamento das necessidades de aperfeiçoamento, assim como uma avaliação dos resultados que são duas das quatro etapas do processo de treinamento.

Então, a sugestão é ter uma política de desenvolvimento que, realmente, estimule e propicie esse retorno do que está dando, quais são os resultados. Por isso, é importante a avaliação do aperfeiçoamento; hoje, ainda não tem parâmetros. A gente não tem um diagnóstico do que acontece antes da ida do indivíduo e quando ele volta do aperfeiçoamento, no seu ambiente de trabalho (D3).

Para alguns entrevistados, a UFV deveria entender a importância do aperfeiçoamento de seus STA, bem como criar meios que facilitassem sua realização, incluindo-o como parte de seu planejamento. Além disso, deveria proporcionar condições para que o técnico, ao retornar, usufruísse de benefícios como ganhos financeiros e promoção dentro de uma carreira, inclusive, assumindo cargos de gestão desde que fossem coerentes com o aperfeiçoamento. Além disso, foram apontadas outras sugestões, como a necessidade de considerar as classes de apoio, médio e superior no aperfeiçoamento, incluindo a criação de um programa para os níveis de apoio e médio, além de oportunidades para o aperfeiçoamento, com afastamento remunerado das atividades. Os entrevistados declararam, também, a necessidade de uma mudança da percepção de concorrentes, que os docentes têm em relação aos STA. Estes devem ser vistos como aliados dos docentes, uma vez que possuem formação semelhante e têm muito a contribuir para a instituição.

\section{Análise geral do aperfeiçoamento na UFV}

A respeito da forma como o processo de aperfeiçoamento vem sendo tratado pela UFV, constatou-se que este não é, apropriadamente, conduzido. Segundo a maioria dos entrevistados isto é devido à falta de uma política de aperfei- 
çoamento institucionalizada, o que resulta em um processo desestruturado, desprovido de regras bem definidas, incentivos e apoio da instituição, que orientem o STA interessado nesse tipo de qualificação. Segundo D1, o fato de a UFV não possuir uma política de aperfeiçoamento institucionalizada é consequência da carência de profissionalização da área de recursos humanos no setor público, especialmente no que se refere à política de desenvolvimento de pessoal. Além disso, a legislação vigente não permite a mudança de cargos para o STA que se aperfeiçoa, existindo, também, a insuficiência de incentivos financeiros tanto para fazer o aperfeiçoamento como em termos de ganhos salariais, após sua realização. As iniciativas para mudanças nesse cenário ocorreram na década de 1990, com a reforma do Estado que, segundo Gaetani (1998), teve como um de seus propósitos oferecer uma atenção especial à questão dos recursos humanos.

A falta de uma política de aperfeiçoamento tem como consequência a inexistência de um planejamento para esse processo, conforme exposto por alguns treinados. Realmente, percebeu-se que, entre as quatro etapas que, segundo Gil (2001), Chiavenato (1994) e Carvalho (1988), constituem o processo de treinamento (diagnóstico das necessidades, planejamento, execução e avaliação), apenas a execução faz parte da realidade do aperfeiçoamento na UFV. Isso fica evidente pelo fato de não existir um levantamento das necessidades de aperfeiçoamento, em cada órgão da instituição. Somente a partir desse diagnóstico, é possível elaborar um planejamento com o estabelecimento de objetivos e meios para alcançá-los por meio do aperfeiçoamento. A última etapa, que consiste na avaliação do processo para verificar se os propósitos foram atingidos, também não existe na UFV.

Quanto aos resultados do aperfeiçoamento para os STA, verificou-se que, em termos de ganhos pessoais, estes foram, em geral, positivos para os treinados, uma vez que suas expectativas foram atendidas na maioria das vezes. Isso demonstra que o aperfeiçoamento, de certa forma, atingiu os objetivos no sentido de proporcionar uma melhor qualificação aos treinados. Em se tratando dos efeitos do aperfeiçoamento para a instituição, percebeu-se um consenso entre os entrevistados de que este, de alguma forma, traz ganhos para a UFV, que adquire um quadro de pessoal mais preparado para atender à sociedade. Cabe mencionar que algumas opiniões foram mais realistas, demonstrando a existência de situações em que os resultados são positivos e outras em que estes não são tão satisfatórios. As situações, que trouxeram resultados positivos para a UFV, foram aquelas em que o aperfeiçoamento do STA foi coerente com o cargo ocupado, pois, ao retornar do aperfeiçoamento, o treinado conseguiu aplicar os conhecimentos adquiridos nas atividades que realiza. 
Por outro lado, existem também situações que contrapõem a anterior, nos casos em que o STA realizou o aperfeiçoamento em uma área, que não está diretamente relacionada a seu cargo. Assim, ao retornar à instituição, ele quer mudar para um cargo que seja coerente com seu aperfeiçoamento. Como a legislação não permite a mudança de cargo, a não ser por meio de novo concurso público, tem-se um problema para a UFV, pois, ela não terá um retorno direto do investimento feito no aperfeiçoamento do técnico e, ao mesmo tempo, pode ter um funcionário insatisfeito por não conseguir utilizar os novos conhecimentos. Verificou-se a existência de casos em que a dificuldade na aplicação dos novos conhecimentos está relacionada não apenas à coerência entre o aperfeiçoamento e o cargo ocupado, mas, também à falta de organização da instituição, no sentido de definir o que ela quer que o técnico faça. Isso contribui para que o STA faça um aperfeiçoamento em sua área de atuação, mas não dê o retorno que poderia à instituição. Nessa situação, observam-se resultados negativos para a UFV, assim como para o STA, que não se sente valorizado após o aperfeiçoamento.

No que se refere à forma como a legislação pode interferir no processo de aperfeiçoamento, percebeu-se que, de certa forma, as leis funcionam como um elemento dificultador, pois não existe um plano de carreira que contemple as necessidades do STA em termos de ascensão pela qualificação, permitindo a mudança de cargo. Além disso, faltam regras que definam como deve ocorrer esse processo. Esta situação da legislação começou a melhorar com o surgimento da Lei no 11.091/2005, que encontra-se em fase de implementação.

Essa lei trouxe alguns avanços na questão do aperfeiçoamento, visto que reconheceu, formalmente, a necessidade de aperfeiçoamento do STA nas Ifes, estabeleceu os tipos de qualificação que cada nível da carreira técnicoadministrativa pode fazer, bem como incentivos financeiros para esses níveis de acordo com o tipo de qualificação realizado. Embora a legislação tenha representado um avanço na qualificação dos STA, não avançou muito em termos de carreira, pois permite ascensão apenas no próprio cargo. Além disso, apresenta alguns problemas no que se refere à valorização salarial do técnico de nível superior (TNS), não reconhecendo os conhecimentos e qualificações dessa classe.

Em se tratando da avaliação do processo de aperfeiçoamento, verificouse que existe apenas o acompanhamento do desempenho do STA durante a realização do aperfeiçoamento, ou seja, ele é avaliado como aluno/treinando. Todavia, após o término do aperfeiçoamento, não existe instrumento formal de avaliação do treinado. Isso deve-se à inexistência de um processo bem estruturado, que contemple as quatro etapas do treinamento, entre as quais 
encontra-se a avaliação como última etapa, para verificar se os objetivos propostos no início do aperfeiçoamento foram alcançados.

Apesar de não existir uma avaliação formal desse processo, os dirigentes declararam que foram percebidos resultados do aperfeiçoamento no desempenho das atividades pelos treinados. Em geral, essas mudanças trouxeram resultados positivos quanto à motivação e desempenho do treinado. No entanto, algumas vezes, essas mudanças não são devidamente aproveitadas pela instituição em razão da dificuldade na aplicação dos conhecimentos. Essas percepções dos dirigentes sobre as mudanças nos STA, após o aperfeiçoamento, constituem um tipo de avaliação dos treinados feita por seus superiores. Segundo Gil (2001), esta é a avaliação do comportamento no cargo, que é realizada após um período em que o aperfeiçoamento foi realizado, quando o funcionário já está de volta ao cargo, desempenhando suas funções.

Diante desse contexto, os entrevistados apresentaram algumas sugestões para o aprimoramento do processo atual de aperfeiçoamento da UFV. Entre elas, destacam-se: a necessidade da criação de uma política de aperfeiçoamento, contemplando o planejamento e as demais etapas do processo; mudanças na legislação no sentido de eliminar as barreiras de progressão e estabelecendo melhores incentivos financeiros para o STA que se qualifica; mais oportunidades para o STA fazer o aperfeiçoamento, inclusive com afastamento remunerado do trabalho; criação de condições para o STA aplicar os conhecimentos adquiridos no trabalho; e maior valorização do STA e seu reconhecimento como treinado.

\section{Considerações finais}

Considerando que esta pesquisa teve como propósito identificar como o processo de aperfeiçoamento dos servidores técnico-administrativos influencia a realização das atividades na UFV, constatou-se que esse processo é composto por diversos elementos que interferem em sua dinâmica, contribuindo para múltiplos resultados, tanto positivos como negativos. Entre esses elementos, estão a falta de uma política de aperfeiçoamento explicitamente institucionalizada, contemplando todas as etapas para a realização do aperfeiçoamento. Além disso, a legislação do servidor público não possui normas bem definidas, no sentido de estabelecer as situações em que serão permitidas e apoiadas as iniciativas de aperfeiçoamento, buscando direcionar e reconhecer a importância do aperfeiçoamento do STA após sua realização. 
Na exposição realizada a respeito da conjuntura de recursos humanos no setor público, especialmente em relação à política de treinamento em Ifes, observa-se que houve alguns avanços, devido à necessidade de mudanças impostas pela reforma do Estado. Embora essas mudanças, como a Lei oㅡ 11.091/2005, representem um progresso na questão do desenvolvimento de recursos humanos, muito ainda precisa ser feito para que a qualificação de pessoal alcance um patamar que atenda plenamente as necessidades da sociedade. Os avanços na área de RH ainda são insuficientes, em razão de não existir políticas integradas de recursos humanos nas organizações do setor público, especialmente nas universidades. A área de $\mathrm{RH}$ precisa ter uma posição estratégica, o que pode facilitar a criação de políticas de recursos humanos integradas, que são essenciais para que os resultados das ações dessa área sejam satisfatórios.

Essa integração é importante em qualquer organização, pelo fato de as políticas de recursos humanos serem interdependentes, ou seja, a forma como determinada política é conduzida, interfere diretamente nas demais políticas. No caso da UFV, as diversas políticas de RH também não são tratadas de forma integrada. Assim, as ações de treinamento, quando existem, visam atender situações específicas, sendo que seus resultados nem sempre são satisfatórios. Outra questão é a autonomia relativamente pequena que a UFV e as demais instituições federais têm para tomar decisões referentes à gestão de recursos humanos. Isso é devido ao fato de as instituições estarem subordinadas às leis federais, que regem seu funcionamento, bem como às decisões em instâncias superiores, que determinam o papel da área de RH nas universidades.

Associado ao contexto em que a UFV está inserida, deve ser considerada a forma de estruturação da instituição que é caracterizada como burocracia profissional, visto que os professores executam e controlam as atividades-fim da instituição. A maioria dos cargos de chefia é ocupada por professores e os conselhos, em geral, são predominantemente formados e presididos por docentes. Os servidores técnico-administrativos não têm tanta prioridade, pois são responsáveis pelas atividades-meio. Tal situação contribui para a pouca atenção que se dedica à criação de uma política efetiva de aperfeiçoamento para os STA na instituição. Assim, um STA que deseja fazer o aperfeiçoamento segue os procedimentos formais criados para os docentes.

Um processo de treinamento bem estruturado deve ter, claramente, definido o retorno que o treinado proporcionará à organização após o término. No caso do aperfeiçoamento na UFV, a situação não é diferente. É importante que a instituição saiba para que o STA vai fazer o aperfeiçoamento, ou seja, que trará futuros benefícios para a instituição. Nesse caso, deve-se considerar cada modalidade de aperfeiçoamento. Isso porque as modalidades de mestrado e 
doutorado estão mais direcionadas para o STA, que vai trabalhar com pesquisa ou docência, enquanto a especialização é mais apropriada para a realização de atividades administrativas.

Em termos de contribuição dessa pesquisa, os resultados podem ser úteis à UFV, auxiliando nas decisões sobre o aperfeiçoamento, buscando seu aprimoramento. Além disso, este artigo possibilitou o conhecimento e entendimento dos elementos que interferem no processo de aperfeiçoamento na UFV. Entretanto, os resultados não podem ser generalizados para outras Ifes, pois, embora estas estejam submetidas à mesma legislação federal, a realidade pode não ser a mesma em função das particularidades de cada Ifes. Um exemplo é a localização da área de RH na estrutura da universidade, que é apresentada em algumas instituições como uma pró-reitoria e, em outras, como a UFV, diretoria de recursos humanos. Dessa forma, sugere-se que sejam realizadas pesquisas em outras Ifes, a fim de verificar se os elementos influenciadores, encontrados nessa realidade, são semelhantes às demais.

\section{Referências}

BARDIN, L. Análise de conteúdo. Lisboa: Edições 70, 1977.

BRASIL. Lei n. 11.091, de 12 de janeiro de 2005. Dispõe sobre a estruturação do Plano de Carreira dos Cargos Técnico-Administrativos em Educação, no âmbito das Instituições Federais de Ensino vinculadas ao Ministério da Educação, e dá outras providências. Diário Oficial da República Federativa do Brasil, Brasília, DF, 13 jan. 2005. Disponível em: <www.planalto.gov.br/legisla.htm>. Acesso em: 22 jul. 2006.

. Decreto n. 5.707, de 23 de fevereiro de 2006. Institui a Política e as Diretrizes para o Desenvolvimento de Pessoal da administração pública federal direta, autárquica e fundacional, e regulamenta dispositivos da Lei n. 8.112, de 11 de dezembro de 1990. Diário Oficial da República Federativa do Brasil, Brasília, DF, 24 fev. 2006. Disponível em: <www.planalto.gov.br/legisla.htm>. Acesso em: 25 jul. 2006.

CARVALHO, A. V. de. Treinamento de recursos humanos. São Paulo: Pioneira, 1988. $276 \mathrm{p}$.

CHIAVENATO, I. Recursos humanos. 3. ed. São Paulo: Atlas, 1994.

. Gestão de pessoas: o novo papel dos recursos humanos nas organizações.

Rio de Janeiro: Campus, 1999. 
FARIAS, P. C. L. de; GAETANI, F. A política de recursos humanos e a profissionalização da administração pública no Brasil do século XXI: um balanço provisório. In: CONGRESO INTERNACIONAL DEL CLAD SOBRE LA REFORMA DEL ESTADO Y DE LA ADMINISTRACIÓN PÚBLICA, 7. Anales... Lisboa, 8-11 out. 2002. Disponível em: <http://unpan1.un.org/intradoc/groups/public/documents/CLAD/ clad0044002>. Acesso em: 8 fev. 2005.

FERREIRA, E. M. Manual de levantamento de necessidades de treinamento. Rio de Janeiro: CNI/Dampi, 1989.

GAETANI, F. Capacitação de recursos humanos no serviço público: problemas e impasses. Brasília: Enap, 1998. (Texto para Discussão, n. 27).

GIL, A. C. Gestão de pessoas: enfoque nos papéis profissionais. São Paulo: Atlas, 2001.

GODOY, A. S. Introdução à pesquisa qualitativa e suas possibilidades. Revista de Administração de Empresas, São Paulo, v. 35, n. 2, p. 57-63, mar./abr. 1995.

GRILLO, A. N. Política de recursos humanos nas universidades federais brasileiras. In: ENCONTRO NACIONAL DOS PROGRAMAS DE PÓS-GRADUAÇÃO EM ADMINISTRAÇÃO, 1990. Anais de Recursos Humanos... Belo Horizonte: Enanpad, 1990. v. 9, p. 91-105.

HARAZIM, P. Planejamento de programas de treinamento. In: BOOG, G. G. Manual de treinamento e desenvolvimento ABTD: um guia de operações. São Paulo: Makron Books, 2001. p. 29-44.

LACERDA, Érika R. M.; ABBAD, G. Impacto do treinamento no trabalho: investigando variáveis motivacionais e organizacionais como suas preditoras. Revista de Administração Contemporânea, v. 7, n. 4, p. 77-96, dez. 2003.

MARCONI, N. Políticas integradas de recursos humanos para o setor público. s.d. Disponível em: <www.top.org.ar/documentos/MARCONI\%20Nelson\%20-\%20 Politicas\%20integradas\%20de\%20recursos\%20humanos.pdf $>$. Acesso em: 5 fev. 2005.

MARQUES, S. M. Processo de capacitação continuada: o caso da Universidade Federal de Juiz de Fora. 2002. Dissertação (Programa de Pós-Graduação em Engenharia de Produção) - Universidade Federal de Santa Catarina, Florianópolis. Disponível em: <http://teses.eps.ufsc.br/Resumo>. Acesso em: 7 jun. 2006.

MILIONI, B. A. Integrando o levantamento de necessidades com a avaliação e validação do treinamento. In: BOOG, G. G. Manual de treinamento e desenvolvimento ABTD: um guia de operações. São Paulo: Makron Books, 2001. p. 9-27. 
MINTZBERG, Henry. Criando organizações eficazes. São Paulo: Atlas, 1995.

NUNBERG, B. Gerência de recursos humanos no setor público: lições da reforma em países desenvolvidos. Cadernos Enap, n. 14. Brasília: Enap, 1998.

OLIVIER, M. Planejamento estratégico e gestão de recursos humanos: casos e descasos nas universidades federais. In: ENCONTRO NACIONAL DOS PROGRAMAS DE PÓS-GRADUAÇÃO EM ADMINISTRAÇÃO, 2001. Anais... Campinas: Enanpad, 2001. CD-ROM.

PACHECO, R. S. Política de recursos humanos para a reforma gerencial: realizações do período 1995-2002. Revista do Serviço Público, v. 53, n. 4, out./dez 2002.

UFV (Universidade Federal de Viçosa). Conselho Universitário. Resolução n. 10/1988. Regulamento de Aperfeiçoamento e Treinamento do Pessoal TécnicoAdministrativo. Disponível em: <www.ufv.br/> Acesso em: 20 ago. 2005.

. Conselho Universitário. Resolução n. 11/2006. Política de Desenvolvimento dos Servidores Técnico-Administrativos da UFV. Disponível em: <www.ufv.br/>. Acesso em: 25 set. 2006.

VERGARA, S. C. Projetos e relatórios de pesquisa em administração. 6. ed. São Paulo: Atlas, 2005. $96 \mathrm{p}$.

YIN, R. K. Estudo de caso: planejamento e métodos. 2. ed. Porto Alegre: Bookman, 2001. 